\title{
Human Capital Analytics: A Game Changer for HR Professionals
}

\author{
M. Rathi Meena, G. Parimalarani
}

\begin{abstract}
In the digital era, Human resource practices has digitally transformed over the last decades. In that human capital analytics is one of the essential elements for HR professionals. Human capital analysis replaces the traditional HR practices. It assists the HR Professional to measure and monitor employees performance. The main function of human resources management is to achieve the goal of the organization through its human capital. Beginning from searching right workforce to retaining the finest workforce, $\mathrm{HR}$ is striving to take smart decisions to recruit the workforce with the help of human capital analysis. The target of this study is to provide insight about the basic concepts of human capital in HR system generally and more exclusively in recruitment system. Human capital analytics provides information to have insight for decision making to support the management of employees in an organization.
\end{abstract}

Keywords: Workforce analysis, decision making, recruitment

\section{INTRODUCTION}

The digital transformation has brought a new dimension in the Human Resource (HR) practices known as Human Capital Analysis ( HCA). It is also known as HR analysis, people analysis, workforce analysis or talent analysis. Taking an effective decision in the business is very crucial for adding value to overall business. While taking a business decisions, managers are demanding accurate information, data, meaningful insights and more information with proper evidence in the analytical representation. The key function of human capital analysis is to enable the HR professional, managers to make better decisions about their workforce. The HR managers will apply the technology, data and statistics at the time of taking decision for recruitment.

Human capital analytics link the workforce's data and business data, which will provide clear connections between them. It assist the managers as well as human resource professional to understand significant data patterns of multiple HR processes and supports better decision making to improve those processes. HR manager often use human capital analysis to obtain insight into workmen behavior, how it is affecting the business and how business results can be improved with data driven decisions. .

\section{REVIEW OF LITERATURE}

Boundreau (2007) Human capital analytics are also termed as labor, workforce, people, and talent analysis. Davenport (2006) Human capital analytics is tool for the HR professional

Revised Version Manuscript Received on 16 September, 2019.

Dr. G. Paimalarani, Associated Professor, Department of Banking Management, Alagappa University, Karaikudi.

M. Rathi Meena, Ph.D Scholar \& ICSSR Fellow at Alagappa University, Karaikudi. to analyze various statistical data, analytical model, quantitative analysis and assist them to take fact based decision making in the organization. Professionals how they utilize, manage, organize is the strategic success of the organization. Employees are how they utilize, manage and organize are increase the recognized as a critical factor to strategic success and competitive advantage of an organization. Lawler (2004) Human capital analytics is process of using statistical tools linking a HR practices to performance of the organization. Becker,Huselid\&Beatty 2009 point out that, Human capital analytics is most powerful tool to take an valid decisions that show the driving forces behind individual and group behavior and their performance level. Masese 2017 Workforce analytics assist the human resource instead of using wide variety of HR data for taking strategic decision in meaningful way and to provide predictive and prescriptive power through workforce analytics.

Objective of the Study:

1. To know about concept of human capital analytics in general HR systems

2. To Scrutinize the functions of human capital analysis in recruitment

\section{RESEARCH METHODOLOGY}

In the current study, the researcher has used secondary data to scrutinize the human capital analysis in general, more specifically in recruitment process and its importance of decision making in the process. The present study is conceptual and exploratory in nature. The secondary data were collected from different research works, articles, and journal.

\section{Data-Driven decision making in HR}

In the era of digital transformation, handling the changes is a crucial one. HR Practices have developed greatly over the last decades. It has moved form an operational discipline towards a more strategic discipline. HR drive the data from demographic profile of the employee, determined salary, employees engagement, employee performance levels are taken then the data is exported from existing system and combined into one dataset which is used to analyze data. 


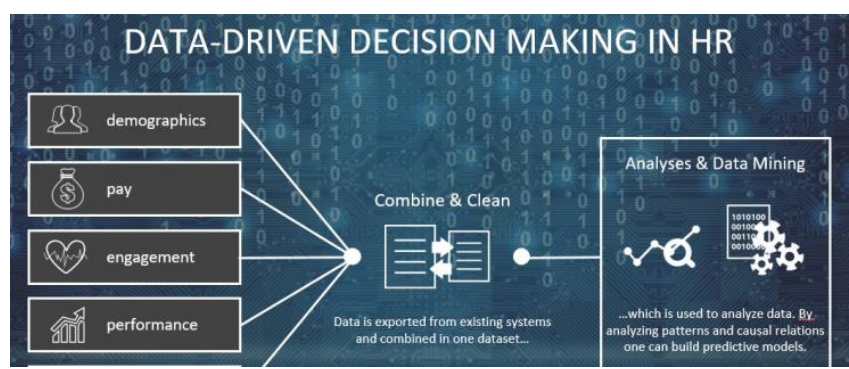

Source: AIHR Academy

Fig.1 Data driven decision making process

\section{HoW TO ANALYSIS THE DATA}

Human capital analytics is a systematic process of converting data into better decision making. It is used to measure and to make an analysis to improve and optimize the employee in the organization ( Fitz-Enz \& Mattox 2014) . There are four main reasons for gathering data to analyze data: Describe, Explain, predict and optimize

\section{HUMAN CAPITAL CAPABILITIES FRAMEWORK}

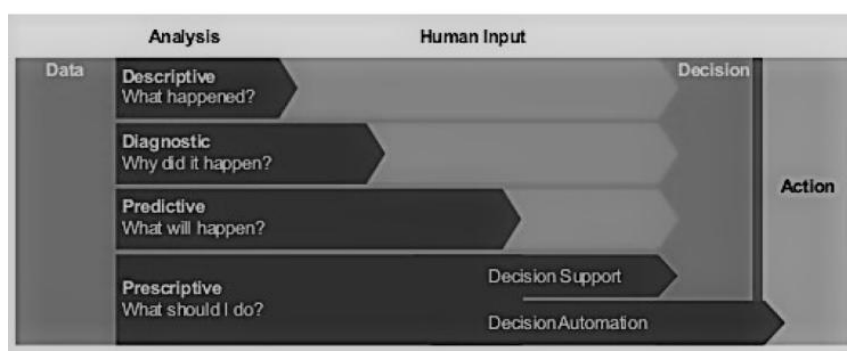

Source: (Gartner 2013)

Fig. 2 Human capital capabilities framework

\section{Descriptive data}

Descriptive data was made by using simple statistical tools such as mean, frequency counts and stranded deviation. This reporting provide a clear insight about the current status of the organization and its provides basic transactional information about human capital in an organization which sum up the performance of the employee in single digit.

\section{Diagnostic}

The primary focus of diagnostics is cost reduction and process enhancement. Diagnostic HR measures describe the current status, historical data patterns and relationships. This report helps to provide answers to the question "What is happing in the organization", understanding the trends and causes of occurrences.

\section{Predictive analysis}

Predictive analysis covers a variety of techniques such as data mining, statistics and modeling by using present and historical data to make prediction about the future. This analysis used to increasing the change of selecting the right candidate, train and promote.

\section{Prescriptive:}

It provides a decision for specific action to achieve the performance. Prescriptive analyze is used to analyze the complex data for predicting outcome, and provide alternative decision.

\section{RECRUITMENT PROCESS IN HUMAN CAPITAL ANALYTICS}

\section{Recruitment process enhances the quality:}

The recruitment process is the combination of performance on production, data on attrition, lifecycle information about employee, and survey feedback on engagement by using these data organization can predict the future performance of the applicant as well as suggest the right hiring channels and budgets based on the specified role.

\section{Efficient Sourcing:}

Sourcing is first stage of recruitment. The major pain point for recruiters and on another hand it will take more time to source the right candidate. Human capital analytics helps the HR teams to optimize their hiring strategies and by removing ineffective sources.

\section{Speed in process and targeted hiring}

Human capital analytics has a significant impact on the speed of hiring. This tool boasts the candidate assessment, can quickly forward to next step, and cut through the unnecessary clutter.

\section{Profiling employees and segmenting with accuracy}

Human capital analysis helps to assess the readiness of every employee by voluminous employee's data on employee's skills, qualification, and years of experience. This ensures the best applicants are hired and new employees are assigned to the appropriate role. By using those data organization understand which employee's demographics admirable and plan employee salary and benefit with future outcome.

\section{HUMAN CAPITAL ANALYSIS CHANGING OTHER FUNCTION IN HRM}

\section{Fine-tune the performance and boost the productivity:}

Identifying the ways to engage and retain the best performer is not a simple task. But it will make the process easy by availability of data analytics. Using analytics, hiring manager can keep a bird eye on employee's performance, progress, employees triumph. Human capital analysis assists the HR manger to improve the individual's productivity and enabling significant cost savings for employers.

\section{Employee sentiment analysis}

This is one of the most important benefits of human capital analytics. This analysis helps the manager to assess how an employee feels about his role and reasonability in the organization with help of using annual survey data and also by tracking an employee's opinion on different area by following his/her data on contribution level in organization.

\section{Upgrade the workforce skills:}

This analysis helps the hr managers to locate the skills gaps on employee's performance and to gain necessary skills to perform the job. 


\section{CONCLUSION}

In present day, all the organization focus their attention on aligning the HR strategy to achieve the goal of the organization. Big data analytics have become essential element for HR professionals for transformation of traditional practices into digital practices. It reduces the work burden for HR professional and assist them to take fact based decision making. Human capital helps the organization to design a strategic employees planning by analyzing the all aspects of manpower data in organization and managing augmented workforce. By using human capital analytics, hr manager can make the decision effectively and it provides a critical insight about their workforce, customers, competitors and outcome of the business in better way. The application of human capital analytics can transform an organization in to more productive by curtailing unwanted cost with appropriate predictive analytical tools. By Human capital analytics not only makes the HR better, but it makes overall business better.

\section{REFERENCE}

[1]. Acito,F.,\&Khatri.V.(2014) Business analytics: Why now and what next? Business Horizons.57(5),565-570

[2]. Boudreau, J. W. \& Ramstad, P. M. 2007. Beyond HR. The New Science of Human Capital. Harvard Business School Press, Boston, Massachusetts.

[3]. Becker, B.E., Huselid, M.E. and Beatty, R.W. (2009), The Differentiated Workforce: Transforming Talent into Strategic Impact, Harvard Business School Press, Boston, MA

[4]. Bernard Marr 2018 Data - Driven HR: How Big Data and Analytics are transforming recruitment https://www.forbes.com/sites/bernardmarr/2018/05/04/data-driven-hr -how-big-data-and-analytics-are-transforming-recruitment/\#3c9cc7a1 $2 \mathrm{~d} 1 \mathrm{f}$

[5]. Davenport, T. H., Harris, J. G. (2006). Competing on Analytics: The New Science of Winning. Accenture. Institute for High performance Business.

[6]. Fitz-Enz J. 2010. The New HR Analytics: Predicting the Economic Value of Your Company's

[7]. Human Capital Investments. AMACOM, New York.

[8]. Fitz-Enz J. \& Mattox, J. 2014. Predictive Analytics for Human Resources. John Wiley \& Sons Incorporated, New Jersey

[9]. Gustafsson, D. (2012). Business Intelligence, Analytics and Human Capital: Current State Workforce Analytics in Sweden. (Unpublished work). University of Sk"ovde, Sweden.

[10]. Gartner 2013. Extend Your Portfolio of Analytics Capabilities. ID:G00254653. Customreport for Gartner customers.

[11]. Human capital analytics, Accenture https://www.accenture.com/in-en/service-fei-digital-hr-transformation -inform-analytics

[12]. Masese Omete Fred Workforce Analytics the Prospect of Human Resource ManagementIOSR Journal of Business and Management (IOSR-JBM) e-ISSN: 2278-487X, p-ISSN: 2319-7668. Volume 19, Issue 11. Ver. V (November. 2017), PP 08-13 www.iosrjournals.org

[13]. Marler,J.H.,\&Boundreau,J.W.1.(2017). An Evidence-based review of HR analytics.International Jounal of Human resource Management,28(1) 3-26

[14]. Mclver,Derrick \&l.Lengnick-Hall , Mark \& A.Lengnick Hall, Cynthia.(2018). A streategic approach to workforce analytics: Integrating Science and agility. Business Horizons.61.10.1016/j.bushor.2018.01.005

[15]. Kumar Rajbhar,Asim.(2017). A study on HR Analytics Transforming Human Resource Management. Journal of Investmentand management. 6.92.10.11648/j.jim.20170604.12

[16]. LAWLER III, E.E., LEVENSON, A. and BOUDREAU, J.W. (2004) HR metrics and analytics: use and impact. Human Resource Planning. Vol 27. pp27-35

[17]. Momin,W.Y.M., \& Mishra,K.(2016). HR analytics: Re-inventing human resource management. International Journal of Applied Research, 2(5), 785-790

[18]. Keerthi,Lakshmi.(2016)'HR ANALYTICS'- AN EFFECTIVE EVIDENCE BASED HRM TOOL.
[19]. Momin, W. Y. M., \& Mishra, K. (2016). HR analytics: Re-inventing human resource management. International Journal of Applied Research, 2(5), 785-790.

\section{AUTHORS PROFILE}

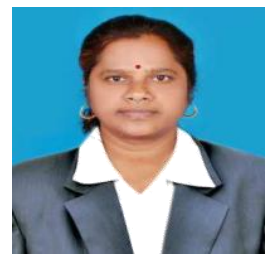

Dr. G. Paimalarani, is presently serving as Associated Professor, Department of Banking Management, Alagappa University, Karaikudi. She holds MBM, MBA, PGDCA, Ph.D in Bank Management. She has 14 years of teaching experience both in national and International level She has travelled to many countries like Singapore, Dubai and Ethiopia. She has the credit of being a member of the fund raising committee of Wollega University, Ethiopia. She has published papers in reputed National and International Journals and presented papers in many conferences including those held at IIM-Bangalore and American University, Dubai Campus- Dubai. She has also enriched her exposure by attending Faculty Development Programme organized by the IIM-Kozhikode. She has organized many national conferences and edited a book titled Emerging Trends in Indian Insurance Sector".

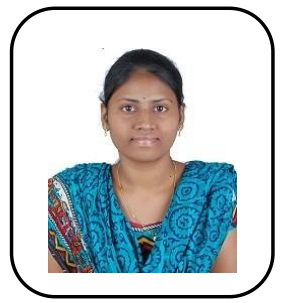

M.Rathi Meena is a Ph.D Scholar \& ICSSR Fellow at Alagappa University. She holds B.Com $\&$ MBA degree. She published many articles in reputed journals, and Presented papers in National and international conferences. She attended many workshop and gained hands on training in statistical tools. 